RAD Conference Proceedings, vol. 4, pp. 7-10, 2020

ISSN 2466-4626 (online) | DOI: 10.21175/RadProc.2020.02

www.rad-proceedings.org

\title{
FORECASTING THE KILOVOLTAGE THERAPY UNIT WITH THE MATHEMATICAL MODEL
}

\author{
Julya Zuenkova ${ }^{1 *}$, Lev Izurov² \\ ${ }^{1}$ Peoples Friendship University of Russia (RUDN University), Moscow, Russian Federation \\ ${ }^{2}$ Sverdlovsk Regional Cancer Clinic, Yekaterinburg, Russian Federation
}

\begin{abstract}
Accessibility is an important part of quality of medical care and depends on the technical resources, infrastructure of a site, clinical stuff and work management. Clinical guidelines for the treatment of non-melanoma skin cancer (NMSC) which define the quality of processes influence work load. Purpose of the study was to determine the clinical and organizational changes in the technology of kilovoltage therapy for NMSC within the dayhospital department after implementation of new clinical guidelines and fraction regimes in compare with previously used schemes; derive a mathematical model of the work for the kilovoltage therapy unit. Materials and methods. Data from the kilovoltage therapy unit of the Sverdlovsk Regional Oncology Dispensary (SROD) were undertaken. Timekeeping was used for calculation the average duration of radiotherapy sessions per patient. The results were evaluated using correlation analysis. To forecast the need for material and human resources, an economic method of mathematical modeling was used. Results. The analysis of the kilovoltage therapy unit of radiotherapy department of the SROD for 3 years showed an increase from 10.4 to 17.3 in the average number of therapeutic fractions per patient after the implementation of the updated clinical guidelines. An increase in the average number of radiotherapy sessions leads to a doubling of the average bed-day of the patient's stay in the day-hospital. The formula was proposed for predicting the work of the unit. There is a clear correlation between the duration of treatment, the dynamics of hospitalization and the number of treated patients. The obtained results using a mathematical model fully correspond to the actual performance of the radiotherapy unit. Conclusion. To ensure optimal availability of medical care, it is necessary to match treatment technologies with available resources of the organization. The introduction of new treatment programs may require the expansion of staff, increase the quantity of medical equipment. The obtained mathematical model of the kilovoltage therapy unit allows to predict the optimal mode of work while maintaining the quality and accessibility of medical care.
\end{abstract}

Keywords: Mathematical model, kilovoltage therapy, radiotherapy, quality of medical care, accessibility of medical care, clinical guidelines, non-melanoma skin cancer

\section{INTRODUCTION}

According to the A. Donabedian concept three components are required to ensure the quality of medical care: infrastructure and technical resources (equipment, staff, working conditions); quality of the treatment and diagnostic process (and it's compliance with local standards); quality of the treatment or diagnostic result, healthcare indicators, economic efficacy etc.

The current healthcare management case study presents the experience of Sverdlovsk Regional Oncology Dispensary (SROD) radiotherapy department.

In 2009, the National Project "Healthcare" was launched in Russian Federation (RF). The aim of the Project was to improve the provision of medical care to patients with cancer. During the 2011 Healthcare Modernization program, new radiotherapy equipment was installed in cancer facilities.

In 2012, the Ministry of health of the RF published an order No. 915n "Procedures and guidelines for oncology medical care" [1], which clearly defines stuff and equipment requirements to radiotherapy departments. In 2018, the Association of oncologists of Russia (AOR) updated clinical guidelines based on the evidence-based medicine [3].

Apparently the new clinical guidelines should influence the organization of the treatment process ensuring its quality and accessibility and need to be in compliance with other local standards as well as with oncology morbidity in the region. The primary incidence of NMSC (non-melanoma skin cancer) in Sverdlovsk region was around three thousand people in 2018 [2]. In the structure of morbidity, skin cancer ranks third in men (8.7\%) and second (13.2\%) in women [2].

Due to the extensive use of kilovoltage therapy and high incidence of skin cancer in the region $[3,4,5,6]$ radiotherapy departments with X-ray units are of particular interest for healthcare management and operational efficacy.

Purpose of the study was to investigate and predict the work of the kilovoltage therapy unit comparing the previously used fractionation method with the new mode according to the updated clinical guidelines.

*zuenkova@bk.ru 
J. Zuenkova, L. Izurov, Forecasting the kilovoltage therapy unit..., RAD Conf. Proc., vol. 4, 2020, 7-10

Derive a mathematical model of the kilovoltage $x$-ray therapy unit.

\section{MATERIALS AND METHODS}

The following data from the kilovoltage therapy unit of SROD were used: number of hospitalizations for non-melanoma skin cancer in 2017, 2018 and 2019 and kilovoltage treatment performed.

For the study only patients with NMSC were included as they were more than $98 \%$ of those treated using the kilovoltage therapy method. The $\mathrm{x}$-ray therapy room operates as part of the radiotherapy Department in a day hospital mode and is designed to serve 800,000 of the attached population according to the local standards [1]. The average number of radiotherapy sessions for each patient was calculated based on the Ministry of Health's reporting data for 2017, 2018 and 2019. The average duration of an x-ray therapy session per patient was estimated and calculated using timekeeping.

To determine the impact of clinical guidelines on the performance, the number of patients treated for NMSC and the average bed-day stay in a day hospital were compared. The results were evaluated using correlation analysis. Method of squares (Pearson) is chosen, since each of the features (bed-day and number of patients) has a numerical expression. The calculations were performed using the jamovi 1.2.12 statistical processing program.

In order to predict and optimize the use of material and human resources, the economic method of mathematical modeling was used. Formulas were derived for calculating the number of treated patients with NMSC by one radiotherapist in the day hospital of the x-ray therapy unit, as well as for calculating the number of hospitalized patients. Based on the derived formulas, experimental (predicted) indicators of the throughput capacity of the kilovoltage therapy unit were calculated.

In this study, informed consent of patients was not required, since the study didn't test any clinical method, but evaluated the implementation of previously approved clinical guidelines.

\section{RESULTS}

Radiation therapy and kilovoltage $\mathrm{x}$-ray therapy in particular are highly demanded treatment methods of malignant neoplasms. While the demand for these are high, the availability of radiotherapy in RF (Russian Federation) still remains low - only $30-40 \%$ of cancer patients receive radiation therapy [7]. Constantly growing needs for radiotherapy, increasing its cost due to the modern high-cost technologies require measures aimed at optimizing the management of patient treatment [8].

The analysis of new local clinical guidelines based NCCN [9] a significant organizational changes within the radiotherapy of NMSC has been observed.
Table 1. Fractionation modes and $\mathrm{x}$-ray therapy doses for NMSC according to the new clinical guidelines of 2018 [3]

\begin{tabular}{|l|c|c|c|c|c|}
\hline Size of tumor & SD, Gy & Fractions & $\begin{array}{c}\text { TD, } \\
\text { Gy }\end{array}$ & Weeks & $\begin{array}{c}\text { TDF, } \\
\text { units }\end{array}$ \\
\hline \multirow{3}{*}{$<2 \mathrm{~cm}$} & 2 & 32 & 64 & $6-7$ & 108 \\
\cline { 2 - 6 } & $3 \cdot 3$ & 15 & 50 & $3-4$ & 108 \\
\cline { 2 - 6 } & 7 & 5 & 35 & 1 & 118 \\
\hline \multirow{2}{*}{$>2 \mathrm{~cm}$} & 2 & 33 & 66 & $6-7$ & 111 \\
\cline { 2 - 6 } & 2.75 & 20 & 55 & 4 & 108 \\
\hline $\begin{array}{l}\text { Adjuvant } \\
\text { kilovoltage } \\
\text { therapy }\end{array}$ & 2 & 30 & 60 & 6 & 100 \\
\cline { 2 - 6 } & 2.5 & 20 & 50 & 6 & 102 \\
\hline
\end{tabular}

As can be seen from the table, the average duration of treatment is 4 weeks, and the average number of fractions per treatment case is 20. Given the proposed fractionation regimens, the average number of bed days that will be required to implement a treatment program of 20 sessions will be 26 .

In 2018, 2091 primary patients with NMSC were identified for the first time in the region, the "rough" incidence rate was 48 per 100 thousand population and correlate with an incidence in the RF [2]. At the end of 2018, 9970 patients were registered for NMSC. In 2018, 1,347 patients received radiation therapy, 692 patients underwent surgery, and 52 patients received combined treatment. Kilovoltage therapy is carried out in 3 branches of SROD. During the practical implementation of clinical guidelines the problem of a significant increase in the load on staff and equipment was identified, and then - the problem of reducing the accessibility of medical care by the growth of patient waiting list.

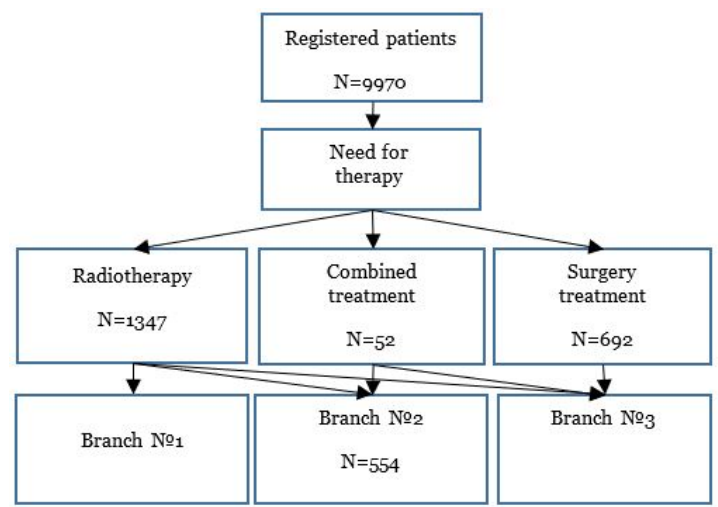

Figure 1. Patients with NMSC routing in SROD

The average quantity of fractions per patient after implementation of AOR guidelines increased from 10.4 to 17.3 , which is 1.7 times more than in 2017. This increase leads to increase of the average bed-day (24 vs. 12). 
J. Zuenkova, L. Izurov, Forecasting the kilovoltage therapy unit..., RAD Conf. Proc., vol. 4, 2020, 7-10

Table 2. Workload of the kilovoltage unit, data 2017-2019

\begin{tabular}{|c|c|c|c|c|}
\hline Year & Patients & Visits & $\begin{array}{c}\text { Average } \\
\text { fractions per } \\
\text { patient }\end{array}$ & Bed-day \\
\hline 2017 & 533 & 5529 & 10.4 & 12 \\
\hline 2018 & 554 & 6925 & 12.5 & 18 \\
\hline 2019 & 728 & 12594 & 17.3 & 24 \\
\hline
\end{tabular}

As can be seen from Table 2, after the implementation of clinical guidelines with an increased amount of fractionations, the load increases significantly $(\mathrm{r}=1,000$ at $\mathrm{p}<0.001)$ - see Figure 2 .

\begin{tabular}{|c|c|c|c|c|c|}
\hline \multicolumn{6}{|l|}{ Correlation Matrix } \\
\hline & & Average fractions & Year & Patients & Bed-day \\
\hline \multirow[t]{5}{*}{ Average fractions } & Pearson's $r$ & - & & & \\
\hline & $\mathrm{p}$-value & - & & & \\
\hline & $95 \%$ Cl Upper & - & & & \\
\hline & $95 \%$ Cl Lower & - & & & \\
\hline & $\mathrm{N}$ & - & & & \\
\hline \multirow[t]{5}{*}{ Year } & Pearson's r & 0.975 & - & & \\
\hline & $\mathrm{p}$-value & 0.141 & - & & \\
\hline & $95 \%$ Cl Upper & & - & & \\
\hline & 95\% CI Lower & & - & & \\
\hline & $\mathrm{N}$ & 3 & - & & \\
\hline \multirow[t]{5}{*}{ Patients } & Pearson's $r$ & -0.916 & -0.982 & - & \\
\hline & $\mathrm{p}$-value & 0.262 & 0.121 & - & \\
\hline & $95 \%$ Cl Upper & . & & - & \\
\hline & 95\% Cl Lower & . & & - & \\
\hline & $\mathrm{N}$ & 3 & 3 & - & \\
\hline \multirow[t]{5}{*}{ Bed-day } & Pearson's $r$ & -0.917 & -0.982 & $1.000^{* *}$ & - \\
\hline & $p$-value & 0.261 & 0.119 & 0.002 & - \\
\hline & $95 \%$ Cl Upper & & . & & - \\
\hline & $95 \%$ CI Lower & & . & & - \\
\hline & $\mathrm{N}$ & 3 & 3 & 3 & - \\
\hline
\end{tabular}

Figure 2. Correlation between the average number of fractions, the average length of hospitalization, and the number of treated patients.

To solve the issue of ensuring optimal working conditions for staff (dynamics of hospitalization) and accessiblity of medical care (the number of patients treated per year), the following formulas have been proposed.

We suggest using the following formula to calculate the number of treated patients with NMSC by one radiotherapist in the day hospital of the kilovoltage unit for a working year:

$a=\frac{N \times K}{n}$

where:

a - number of treated patients per year;

$\mathrm{N}$ - number of calendar days per year (or any time period);

$\mathrm{K}$ - number of patients per working day;

$\mathrm{n}$ - average bed-day.

To calculate the number of patients admitted per week for the kilovoltage therapy, the following formula was proposed: $b=\frac{a \times 5}{N p}$

Where:

a - number of treated patients per year;

5-5 working days a week;

$\mathrm{b}$ - number of patients hospitalized per week;

$\mathrm{Np}$ - number of business days per year

Based on these formulas the following experimental data were obtained.

Table 3. Experimental data on the work of a radiotherapist.

\begin{tabular}{|c|c|c|c|}
\hline Fractions & Bed-day & $\begin{array}{c}\text { Patients per } \\
\text { week }\end{array}$ & $\begin{array}{c}\text { Patients per } \\
\text { year }\end{array}$ \\
\hline 10.4 & 12 & 12 & 608 \\
\hline 12.5 & 18 & 8 & 406 \\
\hline 17.3 & 24 & 6 & 304 \\
\hline
\end{tabular}

There is a clear inverse relationship between the duration of treatment (the average number of fractions per patient) and the predicted number of treated patients per year $(r=-0.917)$. However, the statistical significance of this relationship is low $(p=0.261)$, which requires further study of this topic.

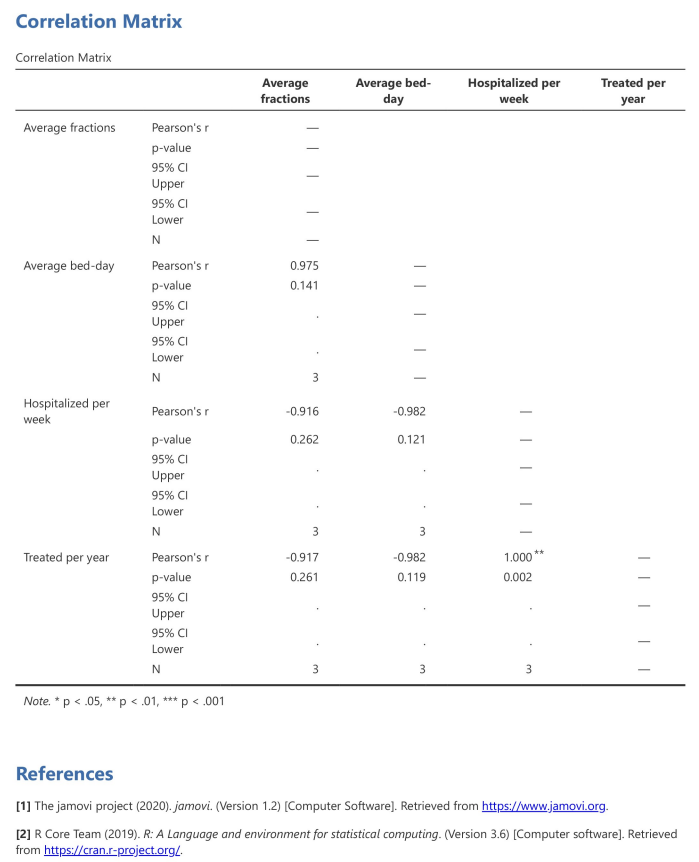

Figure 3. Forecast of the number of treated patients, taking into account the use of new fractionation modes according to the AOR clinical guidelines.

The obtained results using a mathematical model fully correspond to the actual performance of the x-ray therapy room for the period from 2017 to 2019 inclusive.

Historically, until 2018, large-fraction dose regimens were used in medical practice $(\mathrm{SD}=4 \mathrm{~Gy})$ and 
J. Zuenkova, L. Izurov, Forecasting the kilovoltage therapy unit..., RAD Conf. Proc., vol. 4, 2020, 7-10

the average number of required treatment sessions was 10 fractions. Accordingly, the dynamics of patient admissions was 12 or more per week, and during the working year doctor in a full-time mode treated more than 600 patients. In addition, the use of fractionation modes with a high single dose is possible either with a small tumor size, in patients with a low need for cosmetic treatment results, with localization of neoplasms outside the cartilage tissue, with high reparative capabilities of the skin (with a low risk of radiation damage).

In 2019, taking into account clinical guidelines, the average number of treatment sessions increased to 17 , which led to the need to reduce the dynamics of hospitalization to 6-8 per week, while the total number of discharged patients for the year decreased twice compared to 2017 (304 patients). These changes in the treatment process should be taken into account when planning the waiting time for patients to be hospitalized, the load on staff and equipment units.

\section{CONCLUSION}

The study clearly demonstrates that changes in clinical guidelines aimed to improve the effectiveness and quality of treatment, should be taken into account when planning the waiting time for patients to be hospitalized, the load on staff and equipment, which requires additional organizational decisions from the head of the radiotherapy department. There is a clear inverse relationship between the duration of treatment (the average number of $x$-ray sessions per patient) and the predicted number of treated patients per year $(\mathrm{r}=-0.917)$. However, the statistical significance of this relationship is low $(\mathrm{p}=0.261)$, which requires further study of this topic.

To ensure optimal quality and accessibility of medical care, it is necessary that treatment technologies match the available resources of the organization. The new treatment programs may require both an expansion of the staff (medical, nursing), and an increase in the number of units of medical equipment. It is also necessary to study the issue of internal routing of stuff within the radiotherapy department and search for opportunities for more rational redistribution of stuff depending on the load on the modalities used, as well as to solve the issue of routing patients by treatment methods depending on the form, stage, severity of the condition, and requirements for the cosmetic result of treatment. The use of the proposed formulas makes it possible to predict and solve the basic tasks of organizing the medical process of kilovoltage therapy of NMSC with a certain degree of accuracy. The mathematical model of the kilovoltage unit allows to predict the optimal mode of work while maintaining the quality and accessibility of medical care.

\section{ABBREVIATIONS}

RF - Russian Federation

SROD - Sverdlovsk Regional Oncology Dispensary

AOR - Association of oncologists of Russia
NMSC - Non-melanoma skin cancer

NCCN - National Comprehensive Cancer Network

SD - single dose

TD - total dose

Gy - Grey

TDF - time-dose factor

Acknowledgements: The authors would like to thank Sverdlovsk Regional Oncology Dispensary and Peoples Friendship University of Russia (RUDN).

\section{REFERENCES}

1. Order of the Ministry of Health of Russia dated 15.11.2012. No. $915 \mathrm{H}$. «On approval of the Procedure for providing medical care to adults on the profile of «Oncology» (as amended on August 23, 2016, July 4, 2017), registered in the Ministry of Justice 17.04.2013 No. 28163). (In Russian).

2. Clinical guidelines «Basal cell and squamous skin cancer» Ministry of Health of the Russian Federation, 2018. (In Russian).

3. A.L. Lindenbraten, G.E. Ulumbekova Standardization and quality control of medical care [Obschestvennoe zdorovye i zdravookhranenie: Natsionalnoe rukovodstvo]. In: Starodubov V.I. Ed. Public Health and Health Care: National leadership. Moscow: GEOTAR-Media; 2014 452-467. (In Russian).

4. The status of cancer care of Russia in 2018. Ed. A.D. Kaprin, V.V. Starinsky, G.V. Petrova. Moscow: FGBU «MNIII P.A. Herzen» Ministry of Health of Russia, 2019, 236 p. (In Russian). Available at: http://www.oncology.ru/service/statistics/condition /2018.pdf

5. V.N. Volgin, T.V. Sokolova, M.S. Kolbina, A.A. Sokolovskaya. Basalioma: epidemiology, etiology, pathogenesis and clinical picture (part 1). Vestnik Dermatologii i Venerologii. 2013; (2):6-14. (In Russian).

6. S.K. Gantsev, A.S. Yusupov. Squamous cell carcinoma of the skin. Practical Oncology. 2012; 13(2):80-91. (In Russian).

7. V.A. Solodkii, G.A. Panshin, V.M. Sotnikov, A.V. Ivashin. Economic and logistical problems of radiation oncology. Problems in oncology. 2014; 6o(2):6-14. (In Russian).

8. O.V. Morov, A.V. Chernichenko, R.S. Khasanov. Accessibility of radiotherapy at the present conditions of specialized treatment in cancer patients. P.A. Herzen Journal of Oncology. 2016; 5(6):65-70.

https://doi.org/10.17116/onkolog20165665-70 (In Russian).

9. W-J. Koh, B.E. Greer, N.R. Abu-Rustum, S.M. Campos, K.R. Cho, H.S. Chon, et al. Vulvar Cancer, Version 1.2017, NCCN Clinical Practice Guidelines in Oncology. J Natl Compr Canc Netw. 2017; 15(1):92-120. DOI: 10.6004/jnccn.2017.0008 